\title{
Os Intermetatarseum Revisited: A Case Report of Rare Variant and Review of Literature
}

\author{
${ }^{1}$ Rajesh Rachha, ${ }^{2}$ Anand Gorva
}

\begin{abstract}
Os intermetatarseum is the rarest accessory bone of the foot. It is usually found between 1st and the 2nd metatarsal bases arising typically from the base of the 2 nd metatarsal. Only a few symptomatic cases have been reported in the literature, which were either unilateral or bilateral and radiographically they were of different shapes and sizes. We present a large, bilaterally symmetrical and unusual variant of os intermetatarseum. To our knowledge, such large, bilaterally symmetrical, fully formed os intermetatarseum, fusing to both metatarsals has not been described before. The case report also describes the surgical anatomy during the excision of os intermetatarseum and review of the literature to date.
\end{abstract}

Keywords: Os intermetatarseum, Accessory bone of the foot, Metatarsal bar, Deep peroneal nerve compression.

How to cite this article: Rachha R, Gorva A. Os Intermetatarseum revisited: A Case Report of Rare Variant and Review of Literature. J Foot Ankle Surg (Asia-Pacific) 2015;2(1): 47-50.

\section{Source of support: Nil}

Conflict of interest: None

\section{INTRODUCTION}

Gruber first described os intermetatarseum way back in 1877. Ever since, only a few cases of symptomatic os intermetatarseum have been reported. The incidence of os intermetatarseum quoted in the literature from cadaveric and radiological studies ranges from 0.2 to $12.5 \%$. Coskun et $\mathrm{al}^{2}$ identified $0.2 \%$ incidence in a radiographic study among 984 Turkish patients. Cilli found an incidence of $1.2 \%$ in 464 radiographs. Tsuruta et $\mathrm{al}^{4}$ studied the accessory bones of foot and ankle in 3460 radiographs of patients over a period of 7 years and observed that os Intermetatarseum is the rarest of the accessory bones of the foot and ankle with an incidence of $2.6 \%$. Pfitzer ${ }^{5}$ documented a $12.5 \%$ incidence in his report of 520 cadaver dissections. Os intermetatarseum is usually bilateral and arises most commonly from the base of the 2 nd metatarsal. It can be rudimentary or a

\footnotetext{
${ }^{1}$ Clinical Fellow, ${ }^{2}$ Consultant

1,2Department of Orthopedics, Stepping Hill Hospital, United Kingdom
}

Corresponding Author: Rajesh Rachha, Clinical Fellow Department of Orthopedics, Stepping Hill Hospital, United Kingdom, Phone: 01614831010, e-mail: drrachha@gmail.com fully formed bone and can be of any shape or size. ${ }^{6,7}$ In our case, os intermetatarseum represents a large bony bridge between 1st and 2nd metatarsal.

\section{CASE REPORT}

A 14-year-old boy, who does karate at professional level, presented with a 4 months history of pain and prominence on the dorsum of the both feet. Pain aggravates during his karate training and especially when he sits on his heels. He was also complaining of intermittent pins and needles radiating to the 1 st and 2 nd toes.

On examination, he had normal gait, had prominence on the dorsum of both feet (Fig. 1). Both feet have normal medial arch and overall alignment of both lower limbs is normal. Palpating over the prominence caused mild discomfort and was bony hard in consistency. There were no neurovascular deficits, but Tinel's sign was positive on percussing over the base of the swelling. There was no hypermobility of the hallux. He had full range of movement in his ankle, subtalar, midfoot and forefoot. Knees, hips and spine were clinically normal. He had no generalized joint laxity.

Radiographs were obtained which demonstrated bony mass bridging between the first and second metatarsal (Fig. 2). With a differential diagnosis of osteochondroma a further CT scan was performed which clearly demonstrated the fused separate ossification center at the base of the second metatarsal and fully formed os intermetatarseum fused to the first metatarsal (Fig. 3).

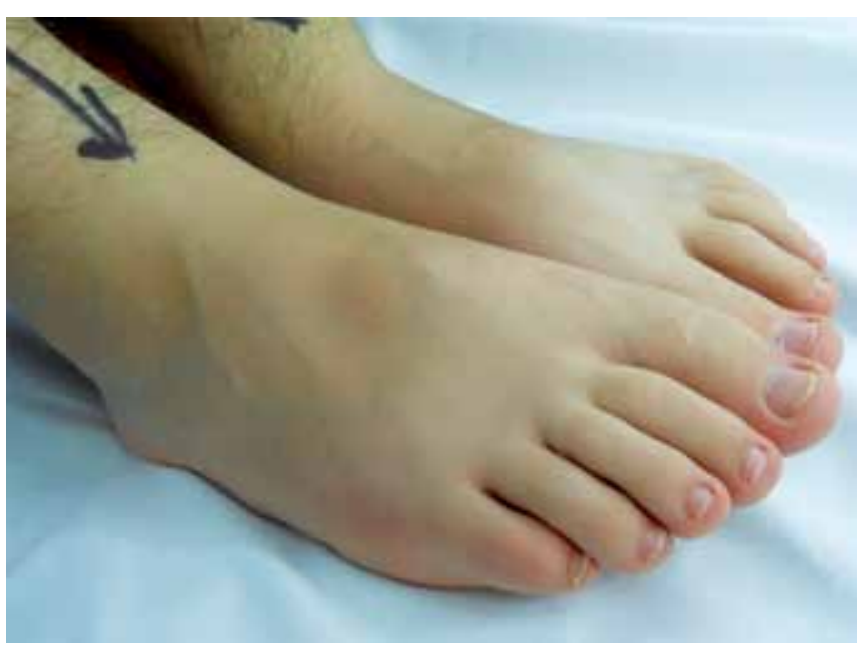

Fig. 1: Prominence over the dorsum of both feet 
After consultation with the parents and with the patient, excision of os intermetatarseum of both feet was performed.

Surgical technique itself is an exercise in dissecting the neurovascular bundle and protecting them throughout the procedure (Figs 4 to 6).

Interoperatively, on both sides we noticed identical findings of inflammation and thickening of the deep peroneal nerve, just above the large os intermetatarseum. Os intermetatarseum itself was found arising from the base of the second metatarsal and extending distally to fuse with the shaft of the first metatarsal distally. This was excised and it measured $5 \times 1 \times 0.5 \mathrm{~cm}$ on both sides (Fig. 6). At 3 months follow-up he was symptom-free and was allowed to go back to sports. At the final follow-up of 18 months he remained symptom-free and was back to his professional karate and plays all other sports without any problems. Radiographs at the final follow-up were normal with no further regrowth (Fig. 7).

\section{DISCUSSION}

Os intermetatarseum is a rare but well-documented accessory bone of the foot. It could be an incidental finding on routine radiographs or diagnosed when they become symptomatic. It can present as unilateral, bilateral, typically arising from the base of the 2nd or 1st metatarsals but can very rarely arise between 4 th and 5 th metatarsals. ${ }^{8}$ Various theories have been put forward. It

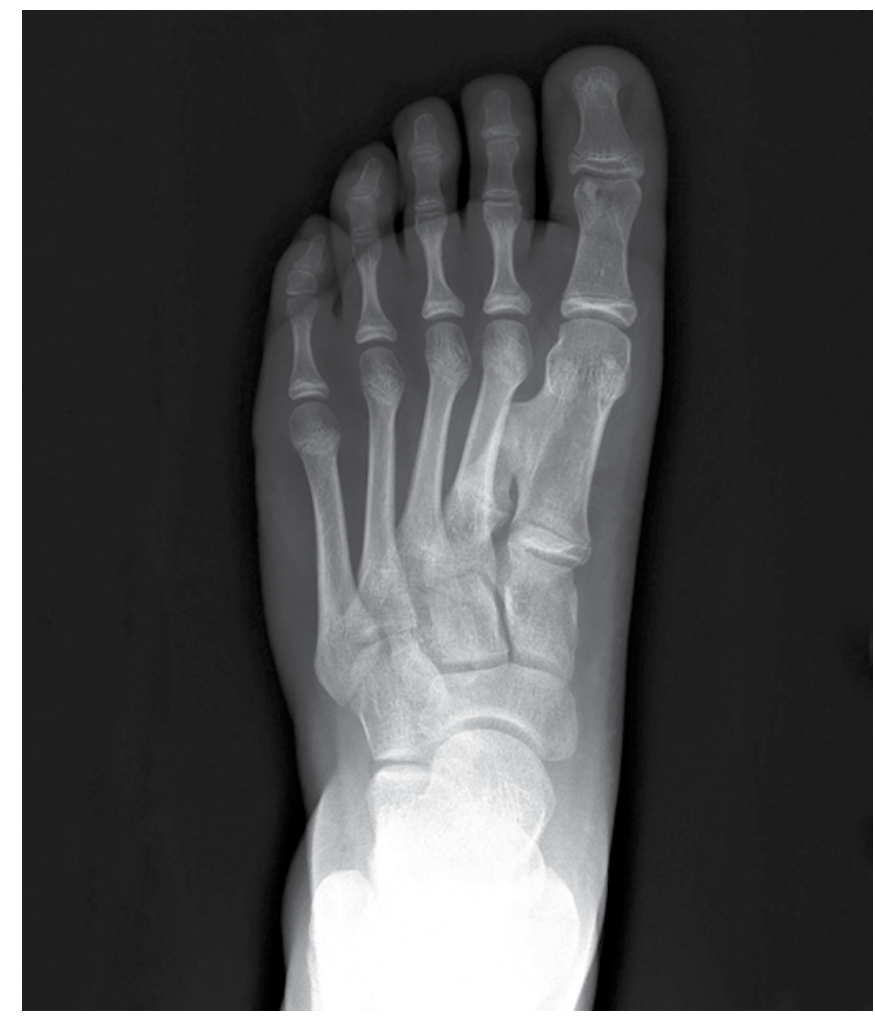

Fig. 2: Os intermetatarseum bridging 1st and 2nd metatarsal

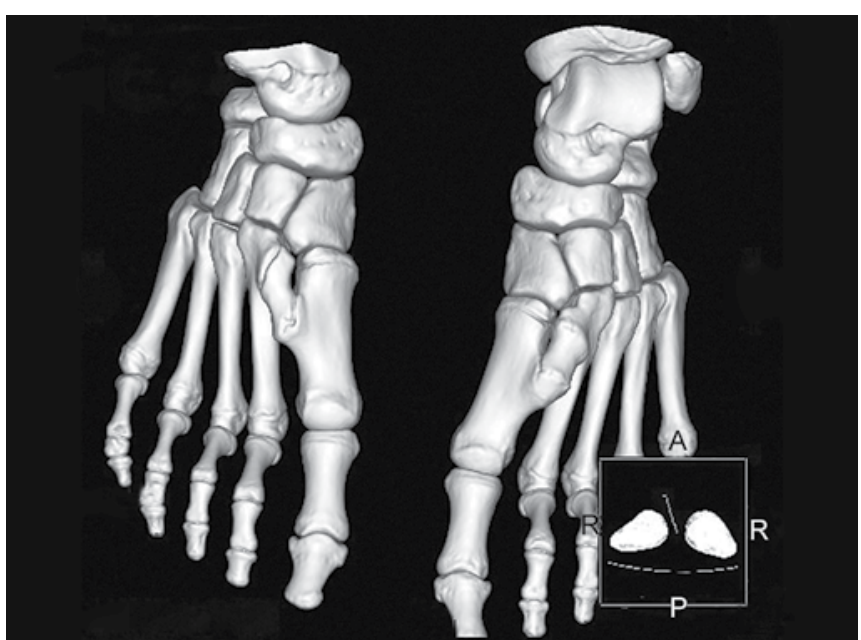

Fig. 3: Computed tomography reconstruction showing os intermetatarseum with ossification center at the base of the 2 nd metatarsal

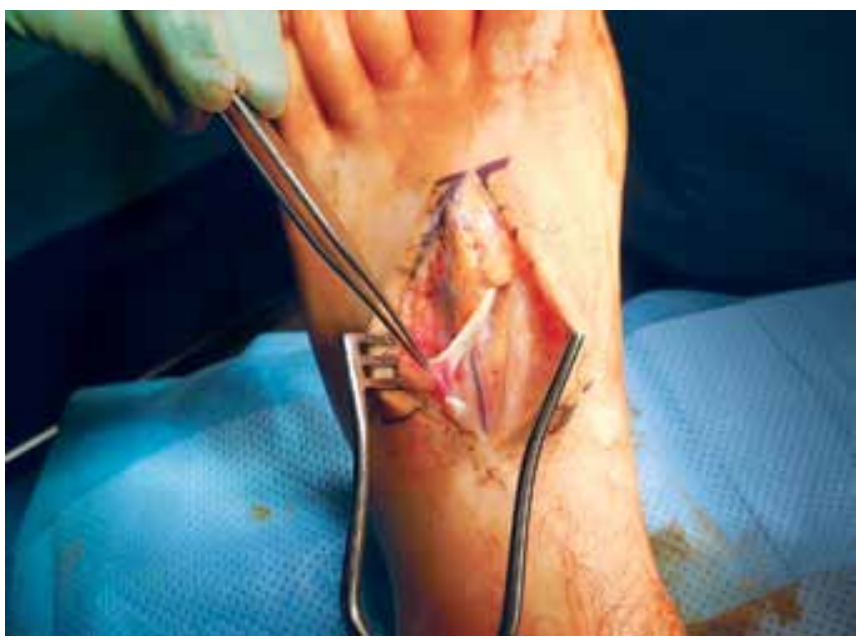

Fig. 4: Neurovasular bundle underneath the EHB

is commonly believed that it is a form of polydactylism. ${ }^{6}$ Henderson $^{6}$ in his article proposed that this bony spur as the lost 1st plantar interosseous muscle and as a contributing factor for the development of the hallux valgus deformity in a case series of four patients. Fried $1^{9}$ believed that it is a sesamoid bone of the first dorsal interosseous muscle from the calcification of the accessory tendon of the dorsal interosseous muscle. Our case demonstrates a complete bar extending from the base of the second metatarsal and fusing to the 1st metatarsal symmetrically in both feet suggestive of probable polydactylism or poly metatarsial etiology.

We did an extensive literature search and found that, from the time it was first described in $1877,{ }^{1}$ only 16 symptomatic cases of os intermetatarseum were reported. Reichmister ${ }^{10}$ presented three cases in a 19, 25 and 44 years old individuals who presented with dorsal foot pain. Knackfuss et al $^{11}$ reported a case of os intermetatarseum, compressing on the medial branch of the deep peroneal nerve in a 52-year-old female patient. Smith and Welch ${ }^{12}$ reported a case of painful 


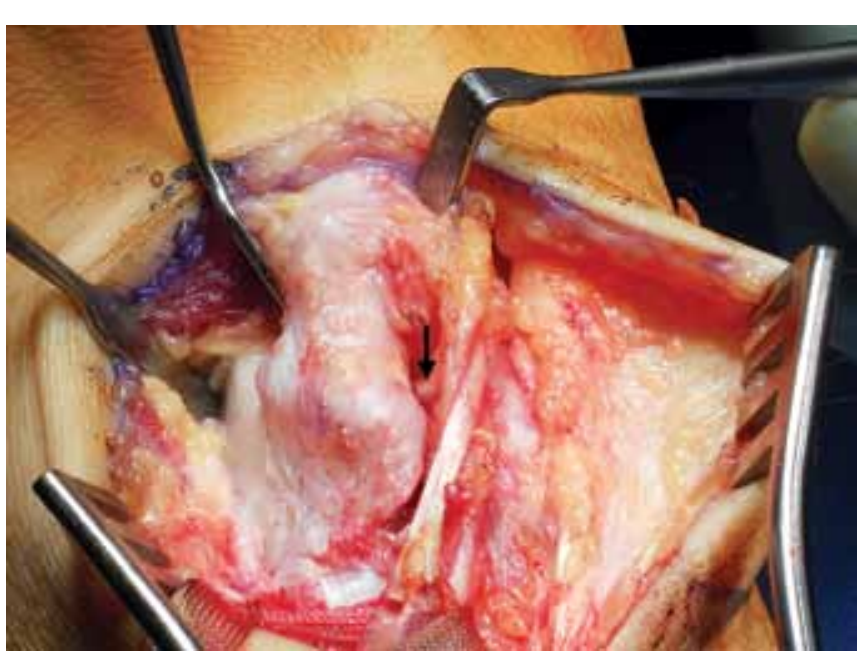

Fig. 5: Os intermetatarseum, between first and the second metatarsal. Arrow showing dorsalis pedis artery in close proximity to os intermetatarseum, coursing in between the base of 1 st and 2nd metatarsal

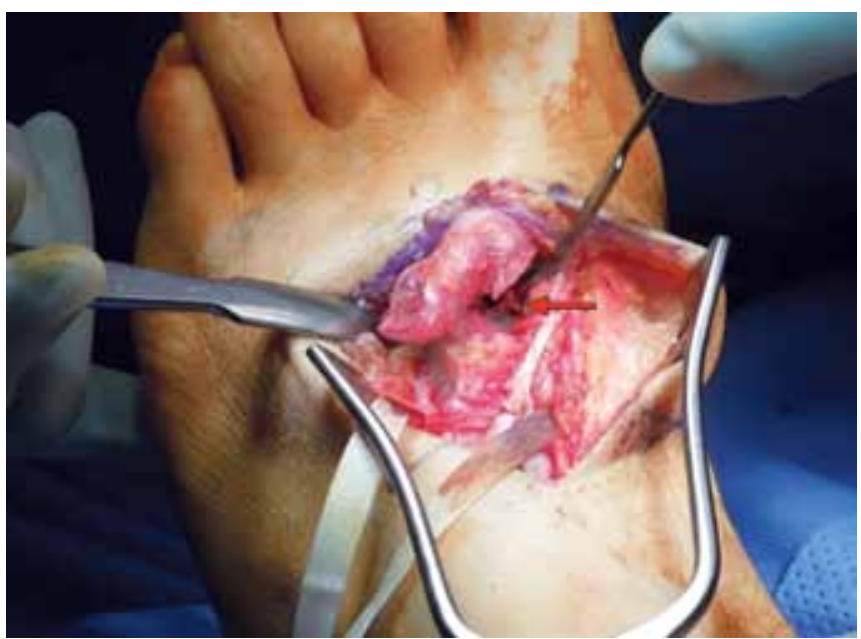

Fig. 6: Excision of os intermetatarseum. Arrow showing dorsalis pedis artery

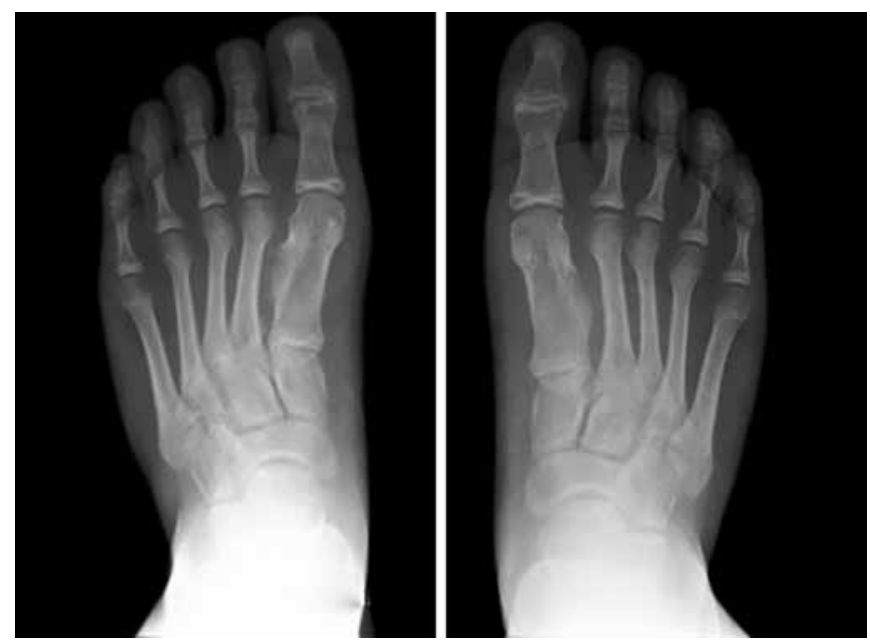

Fig. 7: Postoperative radiograph of both feet at final follow-up

os intermetatarseum without neurologic symptoms. It appears that symptomatic os intermetatarseum is usually presented during preadolescent or adolescent age groups and mainly symptomatic with sport related activities. Nakasa et $\mathrm{al}^{13}$ from Japan described four cases in athletes. Ruffing et al ${ }^{14}$ from Germany described this entity in two athletes. Noguchi et $\mathrm{al}^{15}$ reported a painful os intermetatarseum in a soccer player. Waters ${ }^{16}$ in 1958 and Scarlet et $\mathrm{al}^{17}$ in 1978 reported a case of painful os intermetatarseum. In all these cases, symptoms were consistent with dorsal foot pain or compression neuropathy of the deep peroneal nerve. However, there is evidence-suggesting association between os intermetatarseum, metatarsus primus varus and hallux valgus. ${ }^{6,18}$ Henderson $^{6}$ in his series of 4 patients described metatarsus primus varus and hallux valgus due to os intermetatarseum. Noguchi et $a l^{18}$ reported a case of bilateral hallux valgus associated with os intermetatarseum. Our patient was a 14-year-old karate player with deep peroneal nerve symptoms due to the stretch and compression of the nerve over the os intermetatarseum. In all these cases, symptoms improved after the excision of os intermetatarseum.

Compression of the nerve occurs typically between the os intermetatarseum and Extensor Hallucis Brevis (EHB). EHB forms the key anatomical landmark during the excision of os intermetatarseum. Deep peroneal nerve and dorsalispedis artery lie just underneath EHB (Fig. 4) and can safely be protected by retracting EHB subperiosteally. One needs to be extremely careful in excising the proximal end of the os intermetatarseum, as the branch of the dorsallis pedis artery can be just coursing in close proximity between the base of 1 st and 2nd metatarsal to form the deep plantar arch (Figs 5 and 6).

The deep peroneal nerve branches into medial and lateral branches just distal to the ankle mortise. Lateral branch provides motor innervation to extensor digitorum brevis (EDB) and EHB. Medial branch of the deep Peroneal nerve, courses over the talonavicular joint capsule and lies lateral to the first tarsometatarsal joint, then passes deep to the EHB tendon, where it is susceptible for compression between the EHB and os intermetatarseum. It further continues forward and bifurcates just before it terminates to give sensory innervation to the first web space.

\section{CONCLUSION}

Os intermetatarseum is a rear accessory bone of the foot. Young athletes presenting with dorsal foot pain and symptoms of deep peroneal nerve compression should raise the suspicion of this entity and should be a part of differential diagnosis of the dorsal foot pain. It is best investigated with radiographs and a CT scan. Magnetic resonance imaging scan may be needed rarely if not identified on a radiograph. ${ }^{19}$ Os intermetatarseum can be treated successfully by surgical excision. 


\section{REFERENCES}

1. Gruber W. Uber die beidenArten des uberzahligen Zwischenknochelcheens am Ruckendes Metatarsumunduberdendurch Ankyloseeinesdieser Knochelchenentstandenenund eine Knochelchenentstandenen und eine Exostone am Os cuneiform I und osmetatarsale II vortauchendenFortsatz. Arch Pathol Anat Physiol Klin Med 1877;71:440-452.

2. Coskun N, Yuksel M, Cevener M, Arican RY, Ozdemir H, Bircan O, Sindel T, Ilgi S, Sindel M. Incidence of accessory ossicles and sesamoid bones in the feet: a radiographic study of the Turkish subjects. Surg Radiol Anat 2009;31(1): 19-24.

3. Cilli F, Akçaoğlu M. The incidence of accessory bones of the foot and their clinical significance. Acta Orthop TraumatolTurc 2005;39(3):243-246.

4. Tsuruta T, Shiokawa Y, Kato A, Matsumoto T, Yamazoe Y, Oike T, Sugiyama T, Saito M. Radiological study of the accessory skeletal elements in the foot and ankle (author's transl). Nihon Seikeigeka Gakkai Zasshi 1981;55(4):357-370.

5. Pfitzer W. BeitragezurKenntniss des Menschlichen Extremitatenskelets. IV Die Variationen in Aufbau des Fuss Kelets. Morphologische Arbeiten. 1st ed. Verlag Germany 1986; 245-515.

6. Henderson RS. Os Intermetatarseum and a possible relationship to hallux valgus. J Bone Joint Surg 1963;45-B:117-121.

7. Schinz HR. Roentgen-diagnostics. First American edition, based on the fifth German edition 1951. p. 24.

8. Delano PJ. Os Intermetatarseum: unusual variant. Radiol 1941 July;37(1):102-103.
9. Friedl E. Das Os intermetatarseum und die Epiphysenbildung am Processustrochlearis calcanei. Dtsch Z Chir 1924;188:150.

10. Reichmister JP. The painful os intermetatarseum: a brief review and case reports. Clin Orthop Related Res 1980 NovDec;153:201-203.

11. Knackfuss IG, Giordano V, Nogueira M, Giordano M. Compression of the medial branch of the deep peroneal nerve, relieved by excision of an os intermetatarseum. A case report. Acta Orthop Belg 2003;69(6):568-570.

12. Smith KM, Welch MB. Painful Os Intermetatarseum. J Am Podiat Med Assoc 2010;100(3):213-215.

13. Nakasa T, Fukuhara K, Adachi N, Ochi M. Painful Os intermetatarseum in athletes: report of four cases and review of the literature. Arch Orthop Trauma Surg 2007;127(4):261-264.

14. Ruffing $\mathrm{T}$, Muhm M, Winkler $\mathrm{H}$. The painful os intermetatarseum. Orthop 2011;40(1):93-94.

15. Noguchi M, Iwata Y, Miura K, Kusaka Y. A painful os intermetatarseum in a soccer player: a case report. Foot Ankle Int 2000;21(12):1040-1042.

16. Waters L. Os intermetatarseum: case study and report. J Am Podiatr Assoc 1958;48(6):252-254.

17. Scarlet JJ, Gunther R, Katz J, Schwartz H. Os intermetatarseum-one case report and discussion. J Am Podiatr Assoc 1978; 68(6):431-434.

18. Noguchi M, Ikoma K, Inoue A, KusakaY. Bilateral hallux valgus associated with Os Intermetatarseum: a case report. Foot Ankle Int 2005;26(10):886-889.

19. Kose IC, Hizal M, Bulut EG, Atli E, Ergen FB. Bilateral fused os intermetatarseum presenting as dorsal foot pain: a case report. Surg Radiol Anat 2014 Jul;36(5):503-505.

\footnotetext{
“Please visit www.jfasap.com for instructions to authors and copyright form.
} 